\title{
FEMINISMO, DEMOCRACIA Y CULTURA
}

\author{
EVA MARTÍNEZ SAMPERE \\ Universidad de Sevilla
}

Fecha de recepción: 13-10-2008.

Fecha de aceptación: 27-10-2008.

\section{Introducción}

El feminismo ilustrado ha sido la condición necesaria para que haya democracia y, a su vez, la democracia es el único sistema político que puede garantizar la igual dignidad humana de cada persona y su igualdad en derechos para desarrollar libremente su personalidad, como establece por vez primera a escala internacional la Declaración de Derechos Humanos, de 10 de diciembre de 1948, que prohíbe, por tanto, cualquier discriminación por razón de sexo, entre otras. Sin embargo, la inserción de esta invención filosófica, mediante un pacto político, en la normativa internacional, comunitaria y en las Constituciones democráticas, no ha sido suficiente para acabar con la desigualdad social entre féminas y varones que estructura el patriarcado. La transformación de la sociedad necesita de la acción de los poderes públicos para crear las condiciones de igualdad exigidas por las normas jurídicas Las Constituciones democráticas les imponen ese mandato para desarrollar todas las potencialidades del principio de Igualdad y No discriminación, que es el núcleo de la articulación política y jurídica del Estado democrático, pero que encuentra muchas resistencias para desplegar su eficacia, sobre todo en el terreno de la igualdad de los sexos, dado que su logro supone pasar de un modelo social dominador, basado en la guerra, a un modelo social solidario basado en la cooperación. El patriarcado se defiende presentando la pobreza y la exclusión social como inevitables y acudiendo a teorías como el multiculturalismo comunitarista y la defensa de la identidad cultural del grupo.

Para intentar delimitar cuáles son los problemas y esbozar un camino para hacerles frente, voy a hacer un planteamiento general de la situación (2); 
después me referiré al pensamiento feminista como garante de la igualdad efectiva de mujeres y hombres (3), y, por último, haré una conclusión para dejar claro el reto que supone esta ingente tarea (4).

\section{Planteamiento general}

Dado el peso de varios milenios de la concepción sexista de la especie humana, que subordinaba las féminas a los varones, y, por tanto, la persistente desigualdad social entre unas y otros, a la Declaración Universal de Derechos Humanos hubieron de añadirse -además de la normativa general de desarrollo de la misma, el Pacto Internacional de Derechos Civiles y Políticos, y el Pacto Internacional de Derechos Económicos, Sociales y Culturales, ambos de 1966-, otras normas encaminadas de modo expreso a acabar con esa desigualdad, como el Convenio de Derechos Políticos de la Mujer, de 1952; la Convención para la Eliminación de todas las Formas de Discriminación contra la Mujer, 1979; la Convención sobre los Derechos del Niño, de 1989, entre otras. Y en 1993, en Viena, Naciones Unidas tuvo que afirmar de nuevo que los derechos humanos proclamados en la Declaración eran para féminas y varones, y no sólo para estos últimos, y decidió incorporar la perspectiva de género para su adecuada interpretación y desarrollo en todas las esferas de la vida humana.

Estos avances en la normativa internacional, de la Unión Europea y las Constituciones democráticas, no pueden desplegar toda su eficacia debido a las condiciones de pobreza en grandes zonas del planeta o de bolsas de exclusión social en los países democráticos. Es una situación terrible, pero que puede advertirse claramente. La sociedad va empujando a los poderes públicos a que actúen en ese sentido a escala local, regional, nacional e internacional $^{1}$, aunque la crisis económica, por desgracia, puede suponer un freno a estas políticas. Esta ausencia de condiciones de vida digna está interconectada con la explotación y despilfarro desmedidos de los recursos naturales, que pone en gravísimo riesgo la propia supervivencia el ecosistema de la Tierra, pero -como acabo de escribir- es algo que se percibe con facilidad. El problema es que no hay una voluntad política decidida para cambiar las cosas.

Sin embargo, hay otra dificultad mucho más difícil de percibir, que se presenta con un barniz pretendidamente progresista, y, por eso, cuesta más

1. Vid. la Declaración del Milenio, de Naciones Unidas; el propósito de declarar el año 2010 Año de lucha contra la pobreza, etc.; MARTínez SAMPERE, E., «El concepto de ciudadanía y la creación de las condiciones de igualdad», en GÓMEZ TORRALBO, R. (coord.): Estado de Bienestar y Gobernanza, Sevilla, Instituto Andaluz de Administración Pública, 2007, 36 y ss. 
captar la regresión inmensa que supone en cuanto afirmación del patriarcado, debilitado ya por la teoría y la acción de los movimientos de las mujeres y los varones feministas y por la normativa jurídica que incorporó sus logros. Me refiero a las elaboraciones teóricas del multiculturalismo comunitarista, que defienden la preservación de la identidad cultural del grupo. ¿Quién o quiénes definen qué es la identidad cultural? ¿Quién o quiénes definen qué es el grupo -o la minoría- y quiénes forman parte del mismo?

Para tener una idea más clara de lo está implícito en esta construcción teórica y de sus consecuencias para la articulación de la convivencia humana, es necesario tener en cuenta que, como ha estudiado la socióloga, antropóloga y jurista Riane Eisler ${ }^{2}$, la guerra como elemento estructurador de la sociedad no ha existido siempre. No voy a extenderme en este punto, dado el espacio de que dispongo, pero sí quiero decir que Eisler documenta de modo muy completo cómo hubo sociedades, en lo que Marija Gimbutas llama la Europa Antigua, i.e., hace unos 5.000 años, antes de las invasiones de los aqueos y los dorios y, en Creta hasta hace unos 3.400 ó 3.200 años -el lugar donde más perduraron-, consideradas prepatriarcales, que adoraban a la Diosa, que celebraban la vida y el nacimiento, en lugar de la guerra y la muerte, en las que mujeres y hombres habían vivido como iguales, y que alcanzaron un alto grado de refinamiento. En las pinturas rupestres del paleolítico superior no aparecen armas ni escenas alusivas a la guerra, y Eisler demuestra de modo exhaustivo cómo lo que muchas veces se ha tomado por lanzas son en realidad representaciones vegetales muy estilizadas. Por otra parte, los restos arqueológicos hallados demuestran que no había casi diferencias en los enterramientos de mujeres y hombres, ni tampoco una fuerte estratificación social. No se les enterraba con armas, no se sacrificaba a mujeres o sirvientes en ellos, ni se han encontrado señales de armas en las tumbas. Asimismo, no había esclavitud. Las ciudades no estaban fortificadas ni amuralladas, lo que hace pensar que las guerras no eran algo habitual. Sí se ha comprobado que se dedicaban al comercio y que hubo, sobre todo en Creta, un extraordinario desarrollo del urbanismo, de la cerámica, alfarería, metales, etcétera.

Todo ello sufrió un vuelco terrible, que Eisler llama truncamiento de la civilización, y que según sus investigaciones y conversaciones con otras personas dedicadas a estos estudios en otros lugares del planeta -como China, América Central-, ocurrió también en esas zonas. Aquí voy a limitarme a Europa. Como he dicho más arriba, las sucesivas invasiones de pueblos

2. El cáliz y la espada, Santiago de Chile, Editorial Cuatro Vientos, octava ed., 2003. Prólogo de Humberto Maturana.

Feminismo/s 12, diciembre 2008, pp. 15-32 
indoeuropeos, primero los aqueos y luego los dorios, pusieron fin de modo violento y terrible a todo eso. No estoy diciendo que esas sociedades fueran idílicas o que no hubiera conflictos y violencia en algún grado. Parece que existieron algunos sacrificios humanos en circunstancias extremas -miedo terrible ante una serie de desastres naturales como maremotos y terremotos-. Lo que quiero resaltar es que la violencia organizada en alto grado contra las mujeres, o contra otros pueblos, i.e., la guerra como modo de vida habitual impuesto por la fuerza a los varones, no existía todavía en esos lugares.

Las invasiones llevadas a cabo por pueblos muy belicosos, los cuales conocían el poder mortífero del hierro usado como arma y tenían dioses masculinos concebidos como violentos y terribles, quisieron acabar con todo lo anterior para imponer su organización más primitiva, estableciendo con ese fin unas condiciones de vida mucho más duras para las mujeres y los varones. Para ellas, porque se quiso acabar con el culto de la Diosa, en su versión monoteísta o politeísta, se las apartó de lo que se consideraba sagrado, y se las subordinó socialmente a los varones. Y para ellos, porque también se les privó del desarrollo de otras potencialidades humanas -en lo que hoy consideramos como vida privada- para fomentar todo aquello que exaltaba la guerra, la violencia, la esclavitud, la crueldad. Pero, como bien resalta Eisler, el lapicero para escribir y rescribir la historia fue aún más poderoso que la espada para poner cabeza abajo a la realidad. Y se nos ha transmitido una versión muy interesada de la convivencia humana para mantener la sociedad patriarcal, que Eisler llama androcéntrica, frente a lo que denomina «gilania», la igualdad de los sexos femenino y masculino.

Han pasado varios milenios, los invasores se fueron refinando, tomando algunas costumbres y logros de los pueblos conquistados. Las diversas invenciones filosóficas, pactadas políticamente e introducidas en las normas jurídicas internacionales después de las hecatombes de las dos guerras mundiales -Carta de las Naciones Unidas, Declaración Universal de Derechos Humanos de 1948, que establece la igual dignidad humana de cada persona y la igualdad en derechos, otorgando a cada una personalidad jurídica en cualquier parte del mundo-, han llevado gradualmente a que hoy en Europa la mayoría de la población rechace la guerra como modo de vida, salvo que en último extremo haya que acudir a ella como medio de defensa. Quiero resaltar que una transformación en el modo de valorar la violencia ha sido posible al menos en una zona del planeta. Claro que el Gobierno del Presidente Bush hijo invadió Irak, pero la guerra se ha considerado ilegal, ilegítima, inmoral y torpe por la vieja Europa. Y por gran parte de la población de otros países, lo cual es mucho. 
La condición de posibilidad para que la gran mayoría de la población europea haya llegado al rechazo de la guerra como modo de vida habitual, ha sido el grado de desarrollo humano alcanzado mediante la educación en valores democráticos y la creación de unas condiciones de vida aceptables para gran parte de la población -si bien es necesario avanzar todavía mucho más-. Todo ello ha hecho que también dentro de nuestras sociedades se admita cada vez menos la violencia como modo de vida institucionalizado, lo cual se consigue tras el aprendizaje forzoso del sufrimiento que conlleva, por su castigo en las normas jurídicas y por la educación para reducir los impulsos agresivos. A ello ha contribuido de modo decisivo el feminismo -no porque las mujeres sean menos violentas genéticamente o los varones más agresivos, sino porque la construcción del orden social patriarcal las excluía de la guerra, las privaba del botín considerándolas como parte del mismo, las convertía en objeto de intercambio entre varones, y reducía la vida de éstos a la guerra como el mayor y más glorioso honor. Se ha estudiado que en las sociedades más guerreras y belicosas es peor la posición de las mujeres y es más dura también la vida de los varones. Los estudios feministas han demostrado cómo el patriarcado es sólo una forma de organización social, no la organización social natural ${ }^{3}$. Después de tantos siglos de convivencia humana, debería estar claro que todas las construcciones sociales son creadas por la acción e interacción humanas y, por lo tanto, modificables también mediante las mismas.

3. Poulain de la BarRe, F: De l'Égalité des deux sexes (1673), reeditado por Fayard, 1984; Wollstonecraft, M.: A Vindication of the Rights of Woman (1792), London, Penguin, 1992; MARQuÉs De CONDORCET: Sobre la admisión de las mujeres al derecho de ciudadanía, Obras completas, París, edición de Arago, 1847-1849, vol. X; STUART MiLl, J. y TAYLOR Mill, H.: Ensayos sobre la igualdad sexual, Barcelona, Península, 1973; De BEAUvoir, S.: El Segundo sexo, Madrid, Cátedra, 1998; Millet, K.: Política sexual, Madrid, Cátedra, 1995; DuHET, P,-M.: Las mujeres y la revolución (1789-1794), Barcelona, Península, 1974; Amorós, C.: Hacia una crítica de la razón patriarcal, Barcelona, Anthropos, 1985; Pateman, C.: The sexual contract, Cambridge, Polity Press, 1988; Mernissi, F: El miedo a la modernidad. Islam y Democracia, Madrid, Ediciones del Oriente y del Mediterráneo, 1992; Nussbaum M. y SEN, A.: The Quality of Life, Oxford Univ. Press, 1993; Puleo, A. H.: Dialéctica de la sexualidad. Género y sexo en la filosofía contemporánea, Madrid, Cátedra, 1992; La Ilustración olvidada. La polémica de los sexos en el siglo XVIII. Condorcet, De Gougues, De Lambert y otros/as. Ed. de Alicia H. Puleo, presentación de Celia Amorós, Madrid, Anthropos, 1993; ValCárcel, A.: La Política de las mujeres, Madrid, Cátedra, 1997; AGACINSKI, S.: Política de sexos, Madrid, Taurus, 1998; CAMPS, V.: El siglo de las mujeres, Madrid, Cátedra, 1998; Nussbaum, M.: Sex and Social Justice, Oxford Univ. Press, 1999; Simón RodríGueZ, E.: Democracia vital. Mujeres y hombres hacia la plena ciudadanía, Madrid, Narcea, 1999; Beltrán, E., y MAQuiEIRA, V.: (eds.), Silvina Álvarez y Cristina Sánchez, Feminismos. Debates teóricos contemporáneos, Madrid, Alianza Editorial, 2001; FreiXes, T. y SEVILlA, J. (coords.), Constitución, Género y Estatutos de Autonomía, Madrid, INAP, 2005.

Feminismo/s 12, diciembre 2008, pp. 15-32 
Han influido también en el rechazo de la guerra los nuevos hallazgos científicos sobre la dinámica del cambio, como escribe Riane Eisler. A veces, a este nuevo conjunto de teorías y datos se le denomina la «nueva física». En ocasiones se le llama teoría del «caos», pues por primera vez en la historia de la ciencia, resalta Eisler, se fija en el cambio repentino y fundamental, que nuestro mundo está experimentando cada vez más. Por supuesto, la evolución cultural humana no es igual que la evolución biológica, pero es importante tener en cuenta que todos los sistemas se mantienen mediante la interacción mutua que refuerza las partes críticas del sistema, y cómo los largos tramos de equilibrio o períodos faltos de cambios importantes se ven interrumpidos por puntos evolutivos de ramificación o bifurcación ${ }^{4}$.

Igualmente ha influido en la condena de la guerra el ecologismo, que rechaza el modelo dominador de expansión ilimitada, que lleva a una explotación de los recursos naturales hasta agotarlos -de lo cual, desgraciadamente, estamos cerca si seguimos a este ritmo-. De este modo, la reflexión sobre el punto crucial del desarrollo humano en el que nos encontramos ha puesto fin a la quimera del crecimiento ilimitado. Es necesario, por tanto, un modelo de desarrollo sostenible, equilibrado y armonioso con nuestro entorno, i. e., solidario.

La condena previa de los otros tipos de violencia a que me he referido es la condición para que también se condene la guerra. Y a su vez, la negación de legitimidad a los otros tipos de violencia exige como punto de partida el reconocimiento de la igual dignidad humana de toda persona, y la igualdad en derechos para que cada una pueda expresar su diferente individualidad dentro del respeto al ordenamiento jurídico del Estado. Esto que hoy nos parece tan claro no ha sido así desde la imposición del Estado Constitucional como nueva forma de organización del poder político. Como es sabido, el contrato social se hizo en la práctica entre varones propietarios, por lo cual las mujeres y los varones no propietarios quedaron fuera. De ahí la prohibición y la persecución tan fuerte de la violencia contra la propiedad. Si bien los varones no propietarios pudieron incorporarse en menos de cincuenta años, gracias a las leyes de extensión del derecho de sufragio, no ocurrió lo mismo con las

4. Vid. los trabajos de Ilya Prigogine -ganador del Premio Nobel-y de Isabel Stengers, en química y sistemas generales, de Robert Shaw y Marshall Feigenbaum en física, y de Humberto Maturana y Francisco Varela en biología. La «nueva física» se ha popularizado por libros como El Tao de la Física y El Punto Crucial, de Fritjof Capra. Biólogos y paleontólogos han escrito nuevos trabajos sobre el cambio evolutivo: Vilmos Csayi, Niles Eldredge y Stephen Jay Gould, y académicos como Erich Jantsch, Ervin Laszlo y David Loye, a los que se refiere EISLER, R., op. cit, xxx y ss. 
mujeres. El mantenimiento de la separación tajante entre la esfera privada -en la que reinaba la desigualdad, puesto que las mujeres, niñas y niños estaban sometidos al marido y padre- y la esfera pública -la de los iguales-, mostraba muy bien qué conflictos se admitían en la vida política del Estado -los de los varones en la esfera pública, protegidos éstos por las normas jurídicas del Estado- y cuáles no se toleraba que afectaran a la convivencia política -los que tenían lugar dentro de las familia, predecididos a favor del varón marido y padre de familia, que tenía la autoridad jurídica conferida por el Estado para ponerles fin, mediante el sometimiento de la esposa y la prole-. Es necesario recordar que la Revolución Francesa puso fin a la servidumbre y prohibió que se pegara a las personas que trabajaban en el hogar, mientras legalmente sí se podía pegar a la propia esposa y a las hijas e hijos. Es muy difícil pero no imposible erradicar este espanto tan arraigado.

En cuanto al medio ambiente, el optimismo desmedido y la ignorancia sobre las consecuencias de la explotación sin límite de la naturaleza en los comienzos de la revolución industrial, nos está llevando al peligro del agotamiento del agua potable, al cambio climático y, por eso, al avance del desierto, al deshielo de los glaciares, etcétera. Y, por ejemplo, hay que tener en cuenta que la intervención humana para alterar el curso de los ríos eliminando los meandros, que hizo que el Rin redujera su recorrido en mil kilómetros, llevó a las nefastas consecuencias de las inundaciones en Alemania hace muy pocos años: llueve, el agua no puede filtrarse hacia la tierra en un río cementado; además, mientras las curvas del río aminoraban la velocidad de las aguas, la línea recta la acelera y lleva al desastre.

Las consecuencias de este modelo social dominador -que conduce al fracaso humano y al ecocidio total- se han estudiado por muchas mujeres y hombres especialistas en los diversos ámbitos de modo muy completo. Todas esas reflexiones y las enseñanzas que se pueden extraer de casos similares en los pasados siglos deberían llevarnos a sustituirlo por un modelo social solidario, el único capaz de garantizar unas condiciones de vida digna a toda la población del planeta.

\section{Hacia un modelo de convivencia solidario mediante el pluralismo democrático}

La transformación del Estado liberal en Estado democrático -si bien manifiestamente mejorable- ha llevado a reconocer a cada persona como portadora de dignidad humana y como sujeto de derechos fundamentales. Ello implica que una persona adulta no debe someterse a la voluntad de otra por ser de sexo femenino; que la educación de niñas y niños no debe estar basada en 
la violencia; y que hay que velar de modo especial por las personas ancianas, enfermas o con discapacidad. Para todo esto existe ya la correspondiente normativa, si bien es insuficiente. Pero está siendo especialmente difícil que la sociedad condene la violencia contra las mujeres por estar muy anclada en la mente humana la supuesta inferioridad de las mujeres ${ }^{5}$, socialmente imbuida en los últimos cinco mil años de patriarcado, humanamente creado y humanamente modificable. Como hemos visto, el patriarcado, como modelo social dominador basado en la guerra, lesivo para féminas y varones no sexistas, otorgaba la supremacía social a los varones adultos, los individuos más capacitados para guerrear. La violencia contra las mujeres puede dejar de concebirse como necesaria para el mantenimiento del modelo social dominador cuando se quiera transformar la convivencia humana, mediante la educación y las políticas públicas, por supuesto, pero es decisivo para la condena social de las agresiones a las mujeres que sean consideradas como un delito cualificado por la especial vulnerabilidad de la posición social de las féminas. En esta línea va la Ley Orgánica contra la Violencia de Género ${ }^{6}$, que quiere proteger también a las demás personas vulnerables: niñas, niños, y personas ancianas, enfermas o con discapacidad. El temor al castigo ha funcionado muy bien como elemento disuasorio en los delitos contra la propiedad y, si hay voluntad política, puede hacerlo asimismo en los delitos contra las personas. Por supuesto, para eliminar de la mentalidad social el sexismo contra mujeres y niñas es imprescindible una educación para la igualdad. Lo mismo que ha servido de modo muy eficaz para transmitir una falsa jerarquía entre los sexos, que subordinaba el femenino al masculino, es el instrumento idóneo para inculcar la igualdad de los mismos. Las cualidades y los defectos son siempre individuales, no van asociados al sexo, la etnia, la religión, o cualquier otra circunstancia personal o social ${ }^{7}$.

El modelo social dominador, hasta nuestros días basado en la guerra como modo de vida habitual, aceptaba también la violencia contra niñas y niños y

5. Vid. Lorente Acosta, M.: Mi marido me pega lo normal, Barcelona, Editorial Ares y Mares, 2001, prólogo de Victoria Camps; FreIXES, T.: «Las Normas de Prevención de la Violencia de Género» (Reflexiones en torno al Marco Internacional y Europeo), Artículo 14. Una perspectiva de género, Instituto Andaluz de la Mujer (IAM), 6 (2001); RUBIO CAStro, A., (coord.): Análisis jurídico de la violencia contra las mujeres. Guía de Argumentación para operadores jurídicos, Estudios 18, Sevilla, IAM, 2003; SOTOMAYOR MORALES, E.: La violencia contra las mujeres. Estudio sobre la situación y características de las mujeres en los centros de acogida. Estudios 15, Sevilla, IAM, 2000.

6. Ley Orgánica 1/2004, de 28 de diciembre, de Medidas de Protección Integral contra la Violencia de Género.

7. Vid. MARTínez SAMPERE, E.: «Educar en la igualdad: las políticas públicas», capítulo de un libro sobre Orientaciones para una educación no sexista, pendiente de aparición. 
entre ellos, contra personas adolescentes y entre ellas, y contra personas ancianas, enfermas o con discapacidad. Se educaba a las niñas para la sumisión al padre, al hermano, al marido, y a los niños se les entrenaba en el uso de la violencia como aprendizaje, y, al que no era lo bastante cruel, se le tachaba de «afeminado». En la adolescencia era todavía peor y la educación masculina incluía como elemento inexcusable el manejo de la violencia como instrumento para «hacerse hombres», lo que abarcaba también la violencia entre los propios adolescentes ${ }^{8}$-que abunda hoy en forma de matonismo escolar, también entre las chicas-.

Este substrato de violencia física, verbal, psicológica y sexual contra las féminas, aceptado durante milenios por el modelo social dominador patriarcal, es lo que está detrás de los intentos de mantener otros modos de articular la convivencia humana, distintos del democrático. De ahí los esfuerzos desesperados para deslegitimar el carácter universal de los derechos humanos y dar cabida a otras concepciones que fragmentan la especie humana en guetos y parten de una supuesta incommensurabilidad de las culturas. Es falso de modo manifiesto, pues todas ellas son patriarcales en su concepción de partida, como ocurría en la sociedades democráticas hasta hace muy poco. Luego el patriarcado es el modelo social común de prácticamente todas las sociedades que conocemos -llamadas culturas por la Antropología-.

Para poder apreciar en profundidad la barbarie del multiculturalismo comunitarista y el menosprecio en algunos casos o la negación en otros de la igual dignidad e iguales derechos a mujeres, niñas y niños en aras de la identidad cultural del grupo, que poco a poco está consiguiendo abrirse paso en algunos Estados democráticos, voy a referirme a dos libros publicados de modo próximo en el tiempo: The claims of culture, de Seyla Benhabib ${ }^{9}$, y Ni putas Ni sumisas, de Fadela Amara ${ }^{10}$. Las autoras defienden respuestas diferenciadas ante el problema.

Empecemos por el libro de Seyla Benhabib. Propone un modelo de democracia deliberativa y ella se considera una teórica de la democracia antes que una teórica multiculturalista. Aprecia la profundidad de las diferencias culturales, pero rechaza el multiculturalismo fuerte, el llamado multiculturalismo mosaico, y propugna que la justicia intercultural entre grupos humanos debe

8. Vid. la novela de Robert Musil, Las vejaciones del joven Törless.

9. The Claims of Culture. Diversity Equality and in the Global Era, Princeton University Press, 2002.

10. Con la colaboración de Sylvia Zappi, Madrid, Cátedra, 2004, traducción de Magalí Martínez Solimán, prólogo de Amelia Valcárcel (en Francia apareció en 2003 con el título Ni putes Ni soumises en Éditions La Découverte, París).

Feminismo/s 12, diciembre 2008, pp. 15-32 
defenderse en nombre de la justicia y de la libertad y no en el de una elusiva preservación de culturas. En principio su razonamiento teórico podría parecer correcto, pero veo un primer problema en el énfasis que pone en las diferencias «culturales» y en que se refiera a la justicia intercultural entre grupos humanos, en lugar de a la justicia en las relaciones interpersonales, sin más.

Seyla Benhabib está a favor de la igualdad democrática en la esfera pública y en la sociedad civil. Se considera universalista, pero es partidaria de la coexistencia de varios sistemas jurisdiccionales para diferentes tradiciones culturales y religiosas y acepta una variedad de diseños institucionales para sociedades con fuertes divisiones étnicas, culturales y lingüísticas. Centrando su atención en los dilemas del multiculturalismo y los derechos de las mujeres en países con tradiciones diversas, alega que mientras esas estructuras jurídicas pluralistas no vulneren tres condiciones normativas, pueden ser compatibles con un modelo de democracia deliberativa universalista. Esas tres condiciones son: 1. La reciprocidad igualitaria. Considera que los miembros de las minorías no deben tener un menor grado de derechos civiles, políticos, económicos y culturales que los de la mayoría. 2. La autoadscripción voluntaria. Cree que en sociedades multiculturales un individuo no debe estar inscrito automáticamente en un grupo cultural, religioso o lingüístico en virtud de su nacimiento, y que es deseable que en algún momento de su vida adulta se le pregunte si acepta seguir siendo miembro de su comunidad de origen. 3. La libertad de salida y asociación. La libertad del individuo de salir del grupo de adscripción no debe limitarse, si bien la salida puede estar acompañada de la pérdida de ciertos tipos de privilegios formales o informales. Sin embargo, la voluntad de los individuos de permanecer como miembros del grupo incluso cuando se casen fuera del mismo, no debe rechazarse. Opina que se debe encontrar acomodo para matrimonios intergrupales y para la descendencia de los mismos, pero no aclara cuáles serían éstos.

La construcción de Benhabib tiene buena intención, pero es injusta e incoherente, como veremos. Yo no la comparto porque, o bien el reconocimiento legal de estos grupos, de estas «comunidades culturales» supone un recorte o una negación de los derechos humanos de cada persona, insertos en las Constituciones como derechos fundamentales individuales, lo cual es inadmisible porque vulnera la igual dignidad humana de cada persona y su igualdad en derechos para expresar su diferente individualidad, o bien su existencia formal no supone ninguna modificación del ordenamiento jurídico del Estado, lo cual está muy bien, pero entonces ¿para qué crearlas? Mucho me temo que si se pretende que existan es para algo y ese algo es el menosprecio o la ne- 
gación de la igual dignidad humana y la igualdad de derechos de las mujeres, niñas y niños que las integrarían, como veremos.

Benhabib se esfuerza, siguiendo a Nancy Fraser, por distinguir las «políticas de reconocimiento» de las «políticas de identidad», las cuales considera cerradas en sí mismas. Y rechaza por ello las consecuencias de la estrategia de la «defensa cultural» en Estados Unidos en el Derecho Penal. Veamos tres ejemplos reales, que toma de Susan Moller Okin. En California una madre norteamericana de rasgos físicos japoneses ahogó a sus dos niños pequeños y después intentó suicidarse. La rescataron antes de que se ahogara. Explicó que en Japón lo que había hecho era una costumbre honorable, dada la infidelidad de su marido. Sólo estuvo en la cárcel mientras era juzgada. Fue absuelta. Es obvio que el asesinato de niños queda impune. En Nueva York, una mujer norteamericana de rasgos físicos chinos es golpeada con una porra hasta la muerte por su marido. Este explicó que su acción estaba acorde con la costumbre china de remover la vergüenza caída sobre él dada la infidelidad de su esposa. Fue absuelto del cargo de asesinato. Es evidente que el asesinato de mujeres queda impune. En California, una joven norteamericana de rasgos físicos laosianos fue raptada de su trabajo en la Universidad estatal de Fresno y fue violada. Su asaltante, un emigrante de la «boat people» que huyó de Camboya y Laos en las últimas fases de la guerra de Vietnam, explicó que en su tribu esta conducta es la manera acostumbrada de elegir esposa. La sentencia fue de 120 días de cárcel -no la pena correspondiente a los delitos de rapto y violación- y la víctima recibió $\$ 900$ como reparación. En la práctica, el rapto y la violación quedan impunes. Benhabib considera que la estrategia de la defensa cultural es contraria a la cláusula antidiscriminación del Derecho norteamericano por dos motivos: trata de modo dispar a individuos procedentes de países extranjeros o con determinados rasgos físicos -ella usa la expresión «culturas» extranjeras-; y discrimina a mujeres, niñas y niños como seres menos valiosos, con menos dignidad humana por su sexo o por su menor edad, añado yo. Benhabib dice además que de esa manera las víctimas de esa misma cultura son tratadas de modo injusto, pero olvida que en las zonas del planeta de donde provienen, las mujeres, las niñas y los niños son menos valiosos que el varón adulto, luego su discriminación jurídica en Estados Unidos es el triunfo de sus costumbres que la autora -y un sector de la antropología, la filosofía y la ciencia política- consideran «cultura». ¿Sería la Inquisición española una costumbre odiosa o un rasgo de la «identidad cultural» española a preservar? Cómo es lógico, una barbarie que conseguimos abolir, demostrando así que las personas y las sociedades pueden y deben transformarse para mejor. 
Seyla Benhabib distingue la creciente influencia de esta «defensa cultural» en el Derecho Penal norteamericano de otras prácticas multiculturales de otros países. En la India, Israel, Australia, y cada vez más Canadá y el Reino Unido, el pluralismo jurídico, i.e., la admisión de que la jurisdicción sobre ciertos aspectos de las acciones e interacciones humanas puede quedar dentro de comunidades culturales diferentes y más pequeñas que el Estado nación, toma la forma de un código de derecho personal y familiar, administrado por estas comunidades culturales, sus tribunales y sus jueces. Generalmente, estas comunidades culturales aceptan un código común penal y civil -incluyendo las leyes que gobiernan la economía- y demandan autonomía jurisdiccional sólo sobre el matrimonio, el divorcio, la pensión, la custodia de niñas y niños, y en algunos casos, la herencia. Benhabib es consciente de que esto supone un pacto entre las élites masculinas de las diversas culturas a costa de la justicia de género, como la llama ella. Pone el ejemplo de Shah Bano Begum, repudiada por su marido musulmán, al que ella demandó para que le siguiera pagando la pensión. El se negó alegando que la había pagado durante dos años y además le había proporcionado una dote. El juicio se centró en si la sección 125 del Código Indio de Enjuiciamiento Criminal era aplicable a las personas musulmanas en la India. La sentencia del Tribunal Supremo indio decidió que sí y ordenó que el marido aumentara la pensión de Shah Bano, pero fue más allá. El presidente del Tribunal, el magistrado Chandrachud, expuso la injusticia hecha a las mujeres de todas las religiones, la conveniencia de tener un código civil común, como el contemplado por el parágrafo 44 de la Constitución Federal india, y se refirió a las previsiones de la sharía que establecen las obligaciones del marido respecto a su esposa repudiada. Si bien se han modificado las leyes que prohíben la discriminación basada en el sistema de castas, que se aplican bajo la jurisdicción federal de los tribunales indios, se ha mantenido en la esfera privada el código de familia basado en la religión. Benhabib se contenta con poner de relieve las contradicciones. Una vez más, a mi juicio, de lo que se trata es de justificar el mantenimiento de vínculos de dominación interpersonales que someten a las mujeres, las niñas y los niños al varón adulto, y los privan de la protección del ordenamiento jurídico común del Estado. Todo ello bajo el disfraz de considerar la opresión de las mujeres bajo el pretexto de la religión, los usos o las costumbres como «cultura» que hay que preservar. Téngase en cuenta que el varón adulto está protegido por los derechos humanos sin ninguna restricción por costumbres morales o religiosas.

Por último, para terminar con los casos tratados por Benhabib, la autora se refiere a la prohibición del pañuelo islámico en Francia. Expone las 
contradicciones que a su modo de ver se plantearían entre la laicidad francesa y el derecho a la libertad religiosa para terminar propugnando que las chicas que llevan el pañuelo islámico han redefinido su significado y lo han convertido de signo de discriminación de las mujeres en una seña de «identidad cultural $»^{11}$. Esto es sencillamente wishful thinking. No es posible, como veremos, como tampoco es posible que alguien se ponga un uniforme nazi en una fiesta de disfraces y que por eso cambie el significado de ese símbolo.

Se observa, en cambio, como la propiedad está protegida con carácter universal frente a cualquier ataque y jamás se ha admitido, por ejemplo, que un anarquista que la considere un robo y atente contra ella sea absuelto porque la «cultura anarquista» condena la propiedad privada. Aquí se pone de relieve como el contrato social que está en el origen del Estado se hizo entre varones adultos propietarios, quedando inicialmente excluidas de la ciudadanía política y subordinadas en la esfera privada las mujeres y las personas menores de edad. He ahí el patriarcado moderno. Se quiere poner fin a las discriminaciones basadas en la clase social o en las castas, pero está resultando mucho más difícil acabar con la distinción entre lo público -la esfera de los iguales- y lo privado -la esfera que admite la subordinación de las personas por ser de sexo femenino y ser menores de edad-, y, por tanto, con la discriminación de las mujeres, las niñas y los niños, defendida ahora bajo el barniz de la «cultura», que no es más que una excusa para que personas que vienen de otras zonas del planeta, tienen determinados rasgos físicos, una concreta religión o ciertas costumbres, las mantengan por encima del ordenamiento jurídico del Estado. A eso lo llamo la barbarie del multiculturalismo comunitarista ${ }^{12}$.

Sheyla Benhabib quiere tener en cuenta las denominadas demandas de ciudadanía diferenciada, y rechaza el consenso superficial liberal, el igualitarismo liberal, las jerarquías de poder que se entrelazan de modo pluralista, lo que Ayelet Schachar llama jurisdicciones multiculturales en todos los terrenos, y aboga -como dije al principio- por el enfoque de la democracia deliberativa.

A mi juicio, la democracia deliberativa es un modelo muy limitado. No sirve porque pretende ignorar el conflicto, como expuso muy bien Chantal Mouffe $^{13}$. La unanimidad es imposible y cuando se produce un conflicto hay

11. Insiste en la misma idea en Another Cosmopolitism, Oxford University Press, 2006, ed. por Robert Post.

12. Sobre el multiculturalismo comunitarista y el relativismo cultural como construcciones sexistas contra las mujeres y racistas, vid. MARTínEZ SAMPERE, E., «Derechos humanos y diversidad individual», Araucaria, 8 (2002).

13. El retorno de lo político. Comunidad, ciudadanía, pluralismo, democracia radical, Barcelona, Paidós, 1999.

Feminismo/s 12, diciembre 2008, pp. 15-32 
que hacer política. Quien ejerce el poder de modo legítimo debe decidir y esto significa imponer una solución para mantener la sociedad democrática. Hay que aplicar el ordenamiento jurídico común del Estado, preciso yo. La obsesión por alcanzar un acuerdo sobre todas las cuestiones o el conformarse con un adecuado proceso de deliberación lo considera Mouffe con toda razón filosofía sin política. Esta autora rechaza también las concepciones comunitaristas-que tampoco admiten el conflicto y exigen la sumisión previa de mujeres, niñas y niños- y las concepciones liberales, y defiende una democracia radical que no sacrifique la libertad individual en aras de un imposible consenso. Pensemos, por ejemplo, que a quienes tengan una ideología nazi, fascista o estalinista no se les exige que compartan los valores democráticos a la hora de aplicarles la ley si cometen un delito. Chantal Mouffe defiende la democracia como sustancia, i.e., con un contenido, frente a la mera democracia como procedimiento. Considera con todo acierto que el pluralismo democrático tiene como límite el respeto y la garantía de los derechos humanos de cada persona.

Frente a la buena voluntad de la construcción teórica de Seyla Benhabib, pero que en la práctica es injusta e incoherente porque no garantiza plenamente los derechos humanos de cada individuo, el razonamiento y la conclusión de Fadela Amara son de una claridad meridiana y respetan la igual dignidad humana de cada persona y su igualdad en derechos para expresar su diferente individualidad.

Fadela Amara cuenta el infierno que viven las chicas francesas de religión musulmana en las barriadas obreras por la opresión de los varones jóvenes de las mismas, los hermanos, pues en los últimos veinte años la figura paterna ha perdido valor a causa del paro, mientras crece el descontento entre la juventud por la caída de la inversión pública en los barrios y las dificultades para conseguir empleo, lo cual empeora sus condiciones de vida y limita sus expectativas. Esto unido a la discriminación que sufren en muchas ocasiones las personas francesas de segunda o tercera generación que provienen del Magreb, y que pueden ser o no de religión musulmana, hace que se cree un ambiente muy represivo contra las chicas dentro de las barriadas por los chicos que, desgraciadamente, no son nada fuera de ellas. Todo esto es el caldo de cultivo de lo que Amara llama los «imanes de los sótanos», integristas que usan una interpretación muy rigorista y extrema de la religión para imponer su concepción machista de la sociedad. Los llama así porque predican en locales subterráneos o en garajes, fuera de las mezquitas. Manipulan a la juventud para sus fines con el pretexto de darles una identidad cultural. El resultado es un control exhaustivo sobre la indumentaria de las chicas: no a los vaqueros, a las camisetas ajustadas, a lo que resalte su feminidad, exigencia de que lleven 
el pañuelo islámico; sobre sus movimientos, idas y venidas; sobre sus relaciones con personas del otro sexo: no pueden salir con chicos de la barriada, ni mucho menos tener relaciones sexuales, si quieren salir con un chico tiene que ser de otro barrio y no dejarse ver con él en el suyo. A las que no siguen este código se les hace la vida imposible, llegando hasta la violación colectiva y el asesinato, sigue denunciando Fadela Amara.

A raíz de una Marcha que empezó el 1 de febrero de 2003 y llegó a París el 8 de marzo, se creó en abril del mismo año la asociación «Ni putas Ni sumisas». Durante el año anterior hubo dos sucesos decisivos. En primer lugar, el 4 de octubre de 2002, el asesinato de Sohane, una joven de dieciocho años que fue quemada viva en un sótano de Cité Balzac, barrio de Vitry-sur-Seine. Como escribe Amara, Sohane, hermosa e insumisa pagó con su vida su negativa a plegarse a las normas del funcionamiento de la barriada, a la ley del más fuerte. Su hermana mayor, Kahina, a pesar del sufrimiento y las presiones, se negó a quedarse callada y denunció la barbarie que acababa de destrozar la vida de su familia. Quiso dar a conocer el destino de las chicas de las barriadas obreras. Unos meses antes, Samira Bellil publicó un libro ${ }^{14}$, un relato en primera persona de las violaciones colectivas, que desde entonces aparecen en titulares en los periódicos. Fadela Amara resalta como aquella mujer estuvo muy sola en su lucha, pero llegó hasta el final. Expresa su gran admiración por ella, por su gran humanidad. Les acompañó en la Marcha. Fadela Amara convenció a varias personas miembros de la Federación nacional francesa de las Maisons des potes ${ }^{15}$, que preside, de la necesidad de organizar una Marcha para denunciar ante todo el mundo las prácticas de estos chicos de las barriadas obreras que, aun siendo una minoría, envenenan la vida en las mismas. El largo recorrido por todo el país se llamó «Marcha de las mujeres de los barrios por la igualdad y contra el gueto». La asociación Ni putas Ni sumisas que surgió de ella está compuesta por mujeres y hombres, chicas y chicos, que quieren que se respete su igual dignidad humana y sus iguales derechos sin que se vean recortados por su sexo, etnia, religión o cualquier otra condición o circunstancia. Defienden la laicidad, la emancipación y la mixidad en la mestiza República francesa. Un planteamiento de pluralismo democrático, que es el único legítimo.

14. Dans l'enfer des tournantes, París, Denoël, 2002.

15. «Casas de colegas». Son asociaciones de barrio creadas al amparo de SOS racisme en distintas ciudades francesas a partir de septiembre de 1988. En julio de 1989 se fundó su federación de ámbito nacional, que preside Fadela Amara. La Federación reúne a unas 300 entidades repartidas por todo el territorio francés y promueve la participación activa de las ciudadanas y los ciudadanos en la vida de las barriadas obreras.

Feminismo/s 12, diciembre 2008, pp. 15-32 
Fadela Amara expresa, analiza y valora muy bien el problema de fondo, pluralismo democrático frente a multiculturalismo comunitarista. La Marcha y sus exigencias fueron apoyadas por muchísimas personas, pero hubo una minoría que evoluciona en una esfera islámica de izquierdas, dice Amara, que llegó hasta las amenazas y las presiones para intentar acallar a la mayoría defensora de la República laica. Como es tan clara y precisa, voy a emplear sus palabras:

Algunos llegaron hasta a insultarme y a denostar a algunas madrinas que tuvieron la valentía de participar en los debates. Otros me acusaron de haber pactado con el neocolonialismo, de haber traicionado a mi comunidad de origen -lo que revela sus verdaderas ideas-y de dejar malparado al Islam, reforzando así de manera perversa y descarada la asimilación Islam/islamismo. Siempre resulta sorprendente constatar que los que pensaban dar la puntilla, incluidos algunos intelectuales conocidos, no proceden de la inmigración; y algunos de ellos sólo conocen la presión social de las barriadas porque fue noticia en un telediario de la noche. Son los mismos que se callaron cuando la mayoría de las chicas de las barriadas, precisamente, empezaron a luchar y siguen luchando por no ceder ante la presión del barrio. También son ellos los que tildan a los «pro-ley» ${ }^{16}$ de racistas e islamófobos: para ellos, el velo no es más que un detalle, uno de tantos en la lista de reivindicaciones globales frente a un sistema deficiente. Desde su punto de vista, ¿cómo es posible que haya quien se atreva a castigar a las víctimas que son las mujeres que llevan velo cuando, todavía hoy, Francia se niega a mirar y a asumir su pasado -e incluso su presente- colonialista? ¡Absurdo, ridículo! Estos argumentos, que han retomado los islamistas, no sirven en nuestras barriadas más que para dar crédito a su discurso: ¡claro que tienen razón, si hasta los intelectuales lo dicen!

Bravo, defensores de las libertades: cuando se les habla de igualdad, están de acuerdo; cuando se les habla de exclusión, contestan que es preciso luchar; pero cuando se les habla de laicidad, balbucean, porque no tienen la valentía de llevar su razonamiento hasta sus últimas consecuencias, que no son otra cosa que la redefinición de la laicidad desde sus pilares. Jamás creyeron en ella como vector de emancipación. No se atreven a afirmarlo en voz alta, porque saben que nuestros conciudadanos los castigarán a través de las urnas. Utilizan otros métodos para imponer sus puntos de vista. Al igual que los islamistas, adulan a todos aquellos y aquellas que son susceptibles de oírles. En sus morbosos cálculos, una parte de la nueva generación sólo goza de su favor si acepta la condición de víctima que tan bien han venido utilizando desde hace muchos años. Llevan el absurdo hasta el colmo de justificar cualquier forma de violencia por el hecho de que una víctima no puede convertirse en verdugo. Los más sabios de estos abanderados de la ideología victimista consideran que el islamismo rampante que conocemos

16. Se refiere la Ley que prohíbe los símbolos religiosos ostensibles en el ámbito público. 
no es sino la expresión de una ruptura con el sistema. Por consiguiente, están convencidos de que hay en él unas energías «revolucionarias» que conviene apoyar. Extraña forma de razonar, cuando hoy sabemos los estragos que provoca el islamismo, en primer lugar en los países musulmanes, y sobre todo a las mujeres. Los movimientos feministas de estos países, y de otros, nos han advertido sobradamente contra esta plaga. Algunos simulan estar ciegos o sordos a la hora de fundamentar su análisis político.

Estos manipuladores piensan y hablan por otros, so pretexto que pertenecen a una corriente de pensamiento que aboga por el diferencialismo y, por consiguiente, por el respeto de las culturas y las tradiciones, aunque éstas atenten contra la integridad física y moral de un individuo. Porque los he visto y los he oído, tengo cada vez más dudas acerca de esta desafortunada unión con el Islam político. Ya no era aceptable que, en nombre de esta ideología, se tolerara la poligamia, la escisión y la desigualdad entre los sexos; menos aún vamos a aceptar la instrumentalización del Islam con fines políticos.

Hoy ya no me cabe la menor duda de que el velo representa el símbolo político contra el que hay que luchar cueste lo que cueste, si no queremos caer en el oscurantismo. Todos los discursos que defiende esta minoría actuante de la que acabo de hablar no son más que hipocresía y mentira. Pretende recuperar a una parte de la juventud, por motivos políticos y electoralistas. Esta fascinación por el número que representan los jóvenes de las barriadas obreras hace que se justifiquen algunas desviaciones graves en la lucha contra el racismo.

Desde esta perspectiva, algunos se negarán a marchar contra el antisemitismo, so pretexto de que hay que abrir la manifestación a todas las formas de racismo. Su memoria es bien corta y selectiva. Se han arriesgado a hacerle creer a la opinión pública que los jóvenes procedentes de la inmigración árabe-bereber-musulmana no se sienten implicados cuando se habla de antisemitismo. Como si esta lucha fuera sólo cosa de los judíos y la lucha contra las discriminaciones de los demás. Bonita manera de encasillar en etnias la batalla por los derechos humanos; esto pone claramente de manifiesto el empeño de algunos por afianzar, aquí y ahora, el comunitarismo y por erigirse en sus portavoces, en particular de los musulmanes. Con ello se cerraría el círculo. Han de saber que la lucha contra el antisemitismo es también mi lucha, y la de miles de muchachas y muchachos que se parecen sorprendentemente a mí, al igual que todas las luchas contra aquello que atenta contra el respeto de los derechos humanos ${ }^{17}$.

Insuperable Fadela Amara. Sí a la interacción, sí a la mezcla, sí al mestizaje. Consiguieron entrevistarse con el ministro y se creó la Comisión Stasi para estudiar este gravísimo problema, y el de los chicos judíos y musulmanes que en las escuelas públicas se peleaban en los recreos por la cuestión palestina. Siguiendo las recomendaciones de la Comisión Stasi, se promulgó la muy

17. Op. cit., 163-166.

Feminismo/s 12, diciembre 2008, pp. 15-32 
necesaria y oportuna Ley que prohíbe los símbolos religiosos ostensibles en la escuela y la administración pública, ley que sólo los integristas, contrarios a la emancipación de las mujeres, rechazan.

\section{Conclusión}

Por todas estas condiciones sociales de partida, es necesario tener claro que no se puede garantizar la igual dignidad humana de cada persona y su igualdad en derechos para expresar su diferente individualidad, i.e., la igualdad de los sexos, fuera del sistema democrático, entendido como un ámbito de convivencia donde debe existir el mayor pluralismo posible, pero dentro del ordenamiento jurídico común del Estado, que debe proteger a cada persona frente a la pretensión de individuos o sectores interesados en hacer valer costumbres, interpretaciones religiosas o usos retrógrados, bajo del disfraz de la cultura, para mantener, restablecer o aumentar la desigualdad social. De ahí que sea tan importante para cambiar conceptos equivocados, la legislación de desarrollo de la normativa internacional, comunitaria -Unión Europea-, de las Constituciones democráticas y de los Estatutos de Autonomía, como la Ley Orgánica 3/2007, de 22 de marzo, para la igualdad efectiva de mujeres y hombres, y la ley sobre igualdad de trato, en proceso de elaboración, que establecen de modo expreso la prohibición de discriminación a cualquier persona por aquéllas y cualesquiera otras causas.

El reto que tienen las mujeres y los hombres en nuestros días es de una nitidez deslumbrante: conseguir la igualdad efectiva de féminas y varones en democracias sin pobreza o exclusión social en todas las zonas del planeta, i.e., implantar un modelo social solidario basado en la cooperación, o barbarie y ecocidio. 